\title{
O papel do jornalismo popular e a relação com a cultura popular
}

\author{
Mariana Pícaro Cerigatto
}

\begin{abstract}
Jornalista, mestre em TV Digital e doutoranda em Ciência da Informação pela Unesp.
\end{abstract}
E-mail:maricerigatto@yahoo.com.br.

\section{Resumo}

A cobertura centrada na agenda e no entretenimento dificulta o tratamento contextualizado e menos estereotipado de temáticas relacionadas à cultura popular. A partir disso, este artigo discute as regularidades do jornalismo cultural e traz as recomendações da Unesco para a valorização de conteúdos relacionados à diversidade cultural.

Palavras-chave: Jornalismo cultural; diversidade cultural; cultura popular; crise no jornalismo.

\begin{abstract}
The media coverage focused on the agenda and entertainment hinders contextualized and less stereotypical treatment of themes related to popular culture. From this, this article discusses the regularities of cultural journalism and brings the recommendations of Unesco for the recovery of content related to cultural diversity.
\end{abstract}

Keywords: cultural journalism; cultural diversity; popular culture; crisis in journalism.

\section{Resumen}

La cobertura de los medios centrada en el orden del día y el entretenimiento dificulta el tratamiento contextualizado y menos estereotipado de temas relacionados con la cultura popular. A partir de esto, este artículo analiza las regularidades del periodismo cultural y aporta recomendaciones de la Unesco para la mejora de los contenidos relacionados con la diversidad cultural.

Palabras clave: Periodismo cultural; la diversidad cultural; cultura popular; crisis en el periodismo.

\section{Introdução}

O advento dos meios de comunicação de forma difusa itensificou a dissolução dos monopólios de cultura, além de agilizar a crise das grandes narrativas representadas pela ciência e pela história. Após a década de 90, observa-se que o jornalismo cultural passou a se engajar por notícias e reportagens que estavam em harmonia com a agenda industrial e televisiva, contrariamente ao caráter crítico e analítico dos assuntos artístico-culturais (MELO, 2012).

Segundo Gadini (2006), no Brasil, grande fatia dos cadernos diários dedicados a temáticas culturais, tem a metade do seu espaço total dedicada à publicação de programação televisiva, os roteiros (como serviços de ventos), e colunas sociais. Sem contar as sessões destinadas a variedades, tais como horóscopo, palavras cruzadas, quadrinhos etc. que ocupam as páginas culturais dos jornais, somando $60 \%$ do espaço aproveitável. $\mathrm{Na}$ análise do autor, reataria, dessa maneira, $40 \%$ de espaço para reportagens ou textos críticos. Não obstante, cadernos e editorias destinadas à "Cultura" nos veículos de comunicação têm priorizado reportagens centradas ainda no chamado "celebrismo" (SEGURA; GOLIN; ALZAMORA, 2011).

Equipes menores nas redações, entre outros fatores, contribuíram para a configuração de um segmento relativamente ausente de reflexão (SEGURA; GOLIN; ALZAMORA, 2011). Diante 
disso, instaura-se uma crise no jornalismo cultural, e é preciso retomar aspectos importantes sobre a sua função e seu papel.

Ligada a essa discussão, uma questão central diz respeito à valorização das culturas regionais e locais pelas editorias de cultura. Diante disso, surgem indagações: as mídias, o jornalismo e as novas tecnologias estão mostrando essa diversidade, a cultura regional e local? Como o jornalismo cultural lida com as vertentes entre o "global", "a cultura de massa" e a "cultura popular"?

Na visão de Moraes (2008), a cobertura da grande mídia a respeito de eventos folclóricos, por exemplo, não dispõe de profundidade e análise. Para a autora, o Brasil abriga uma extensa atividade cultural, pelo fato de agregar em seu território a cultura de vários povos. Mas, segundo ela, o exposto na mídia é incompatível com essa diversidade. E, quando há cobertura de algum evento cultural, como uma festividade folclórica, por exemplo, a cobertura acaba restrita muito mais para uma pasteurização e uma simplificação dos fatos. Há dificuldade em aprofundar ou contextualizar os assuntos abordados.

O objetivo deste artigo é apontar problemáticas enfrentadas pelo jornalismo cultural, assim como suas regularidades e papéis em sociedade, e relacionar a importância deles para se estabelecer uma prática de jornalismo cultural com mais identidade e que valorize mais as culturas locais e regionais.

\section{Desenvolvimento}

\subsection{Breve histórico do jornalismo cultural}

As primeiras coberturas jornalísticas de cultura surgiram por volta do século 17 e 18, na Europa. As primeiras publicações faziam cobertura das obras literárias e artísticas, além de relatarem as novidades sociais (MELO, 2012).

Os primeiros impressos que traziam conteúdos sobre obras culturais datam de 1665 e 1684 . Mas o representante tido como mais "famoso" do jornalismo cultural viria só em 1711, na Inglaterra, com o periódico The Spectator, que tinha o objetivo de "trazer a filosofia para fora das instituições acadêmicas para ser tratada em clubes e assembleias, em mesas de chá e café" (MELO, 2012, p. 01). Assim, “o jornal cobria desde questões morais e estéticas até a última moda das luvas" (BURKE, p.78, 2004).

Percebe-se então que começam a surgir folhetins que abrigavam uma perspectiva mais popular de cultura. Essa postura menos elitista se espalhou rapidamente na imprensa impulsionada pelas transformações possibilitadas pelo processo de industrialização (SEGURA; GOLIN; ALZAMORA, 2011).

Aflorava então o que passou a ser chamado de "jornalismo da empresa capitalista” (MARCONDES FILHO, 2000), devido à redução de preço da impressão e à ampliação do número de exemplares e de leitores.

No Brasil, de forma geral, o desenvolvimento do jornalismo cultural "está associado ao advento do folhetim como fórmula atrativa para incrementar as vendas dos jornais, potencializando a associação entre jornalismo e literatura”. (SEGURA; GOLIN; ALZAMORA, 2011, p. 04) 
Por aqui, Machado de Assis e José Veríssimo se tornam grandes representantes do jornalismo cultural. E ganha contornos mais delimitados tendo sua condução reforçada por outros grandes nomes da literatura, assim como da política e da filosofia, tais como Oswald de Andrade e Mário de Andrade. Em 1982, o jornalismo cultural ganha "expressão máxima" com o nascimento da revista O Cruzeiro (SEGURA; GOLIN; ALZAMORA, 2011).

Feito esse percurso, estamos hoje diante de novos desafios para o jornalismo cultural, que busca solucionar sua "crise de identidade". Isso porque o sentido de cultura foi profundamente alterado nas sociedades contemporâneas. Mas, afinal: quais são as regularidades do jornalismo cultural e como esse papel tem se modificado ao longo de sua história?

\subsection{Mudança de paradigma no jornalismo cultural}

Uma coisa certa a dizer, em meio à crise do jornalismo cultural, é que houve uma mudança de paradigma (ou pelo menos está em processo) em relação ao que é considerado "cultural". Antes se concebia (e, por vezes, ainda se concebe) que há uma cultura "alta" e uma cultura "baixa”, esta de qualidade inferior, que inclui manifestações tidas como populares, ou então massivas, as quais não merecem reconhecimento, apuração e nem análise de sua importância nas práticas sociais (MELO, 2012).

Só seriam merecedores de um tratamento diferenciado os artistas eruditos e as formas artísticas tradicionais. "A designação de 'arte' seria conferida a poucos e seriam esses denominados artistas que mereceriam tratamento mais crítico, interpretativo e analítico do jornalismo" (MELO, 2012, p. 03).

Ao referir-se a este assunto, é bom lembrar que foi a Escola de Frankfurt principal difusora da indústria cultural e de estudos críticos pelo que se entende de "cultura para as massas". Os estudos frankfurtianos despontaram a partir de 1923 com uma linha de pensadores marxistas, na Alemanha. Em 1930, com Max Horkheimer, aderiu-se à postura de investigação crítica da sociedade capitalista moderna (SANTOS, 2003). Ideais marxistas influenciaram os frankfurtianos, assim como o movimento sindical, que teria sido incitado por fatores ligados à Revolução Russa, em 1917. Pensadores como Hegel, Kant, Nietzsche e Freud também teriam sido importantes na trajetória dos estudos.

Com o avanço do partido nazista, os frankfurtianos já não podiam mais se sentir seguros na Alemanha, devido a críticas tecidas contra membros do partido. Ao se deslocarem para os Estados Unidos, o contato com a sociedade de massa e com as desigualdades entre as classes resultou em uma teoria crítica da sociedade. A partir disso, os estudos começaram a fazer menções sobre a indústria cultural - um sistema composto por filmes, programas de rádio etc. para o consumo massivo. Dentre as características da indústria cultural estão a cultura reduzida à mera mercadoria, padronizada, com vistas de atingir o gosto médio do público.

Para Adorno e Horkheimer, (1985), a indústria cultural funcionava como um novo meio de "anestesia social". Pelo fato de funcionar como um sistema administrativo da sociedade capitalista - levando em conta a enorme classe de trabalhadores explorados pelo sistema de produção e mais-valia - este sistema social necessita de uma forma de controle de comportamentos sociais. Nesse sentido, os produtos da indústria cultural são produtos de entretenimento, de "falso lazer", 
com o objetivo de gerar lucros e estimular a venda em larga escala. Por isso, surge a necessidade desta indústria, para ganhar audiência, elaborar produtos que sirvam ao espectador algo agradável, um analgésico passageiro, para que a satisfação seja apenas momentânea, a fim de que surja uma nova necessidade a ser satisfeita por um novo produto (CERIGATTO; SIQUEIRA, 2008).

Cultura de massa e cultura popular eram vistas como meras distrações, conforme Leavis e Thompson (1933) apud Halloran, J. D. e Jones, M. (1986, p. 56):

A distração é melhor exemplificada pela imprensa popular - isso se 'dissipação' não for a melhor palavra ... Nos jornais populares, a tendência dos ambientes modernos é desencorajar tudo que não seja de interesse imediato e raso, as mais superficiais, automáticas e baratas respostas mentais e emocionais são exibidas de modo mais desastroso.

O desenvolvimento tecnológico e a mecanização, neste contexto, eram também vistos como alicerces da sociedade moderna e para a disseminação de produtos massivos tidos como "alienantes". Segundo Leavis e Thompson (1933) apud Halloran, J. D. e Jones, M., (1986, p.55):

O grande agente de mudança e, do nosso ponto de vista, de destruição tem sido, claro, o poder da máquina aplicado. A mecanização nos trouxe muitas vantagens mas também destruiu os antigos modos de vida, as velhas formas e, por causa da rápida e contínua mudança que a máquina envolve, ela impede o crescimento do novo. Além disso, as vantagens trazidas pela mecanização resultaram na estandardização, nivelando a realidade por baixo, como se tudo fosse mero bem material.

Apesar dos estudos da Teoria Crítica terem sido de extrema importância para entender mecanismos de produção de bens culturais, há estudos e visões não consideram que tudo que é veiculado pela grande mídia seja considerado de total vazio valor cultural. Posturas como a do expoente Umberto Eco, em seu livro "Apocalípticos e Integrados", critica os "integrados" (adeptos ao funcionalismo) por omitir questões relativas à cultura de massa, mas também os teóricos chamados por ele de "apocalípticos", que seriam os membros da Escola de Frankfurt. Os apocalípticos são criticados por adotar uma postura de extremo pessimismo e rejeição diante da sociedade e cultura de massa. Para Eco (1979), os teóricos das duas correntes opostas (integrados e apocalípticos) tratam de maneira muito genérica um fenômeno complexo como a cultura de massa, que requer análises mais profundas e equilibradas.

Atualmente, o que vemos é a tendência da diferenciação entre "alta" e "baixa" cultura perder força. Como alega o jornalista Daniel Piza, "a música de um Pixinguinha - negro, pobre, com pouca educação formal - é elitista", ou, ainda, "é óbvio que um filme de Spielberg é cultura" (PIZA, 2004, p. 46). Porém, Magalhães (2010) destaca algumas dessas dicotomias vistas no jornalismo cultural, que ora reforçam a superficialidade de um lado e ora se faz sobressair o eruditismo. O desequilíbrio entre temas considerados "elitistas" e os populares comprometem o papel do jornalismo cultural.

No entanto, em meio esta discussão, é importante ressaltar que existem diferenças entre a cultura popular autêntica e a cultura de massa. Hall e Whannel (1964) consideram importante saber separar o que eles chamam de "cultura popular veiculada pelas mídias" e "cultura de massa". 
Enquanto a cultura popular mediatizada representa uma continuidade da arte anônima produzida em contato com o público, a cultura massificada destrói os laços de individualidade e as idiossincrasias do artista; enquanto a cultura popular permite ao artista exercitar um estilo pessoal reconhecível pelo público, a cultura massificada vende a pessoa do artista, mas não seu estilo pessoal. Como a cultura popular permite que seja estabelecido um elo com o público, o artista acaba se perdendo no meio da sua obra. Já na cultura de massa, a pessoa por trás da produção é que é vendida ao público como mais importante. A cultura popular usa a estilização e a convenção, mas acaba encantando o público ao criar alguma surpresa criativa, apesar das convenções. A cultura massificada usa estereótipos no lugar das convenções e estilizações e o resultado são fórmulas simplistas, planejadas para mobilizar um estoque padrão de sentimentos que mantêm a audiência conectada, mas não necessariamente encantada (CERIGATTO; SIQUEIRA, 2008).

\subsection{Regularidades do jornalismo cultural}

Por mais que o jornalismo cultural tenha sido alvo de mudanças durante sua história, há aspectos que se mantêm vigorosos em sua trajetória. Se recorrermos ao passado, encontramos o que permaneceu, mesmo com o decorrer do tempo e das transformações. De acordo com Melo (2012), nessa busca, encontramos duas regularidades fundamentais. Primeiro, a necessidade de democratizar o conhecimento e, segundo, o caráter reflexivo. São elas que definem o jornalismo cultural como uma prática ímpar e influente para a sociedade.

Vamos pontuar as duas regularidades do jornalismo cultural, baseadas em Melo (2012):

a) Democratizar o conhecimento: Nos primórdios do jornalismo cultural, The Spectator já colocava como compromisso "trazer a filosofia para fora das instituições acadêmicas para ser tratada em clubes e assembleias, em mesas de chá e café" (BURKE, 2004, p. 78). Nesta perspectiva, o jornalismo cultural surge com o "ofício" de mediar o conhecimento e torná-lo mais próximo e familiar do maior número de pessoas. O que antes era restrito e acessível a uma elite, começa a circular por outras camadas sociais. Essa regularidade é fundamental até nos dias de hoje, mas é preciso rechaçar uma linguagem elitista e aristocrática. Gullar (2002, p.19) registra bem essa ideia dizendo que

ora, se os críticos defendem que abandonar essa linguagem, com seus requintes, é baixar a qualidade da obra e trair a cultura, o único caminho que deixam é continuar a escrever para a minoria. Noutras palavras, só existe arte para uns poucos e raros. É claro que não concordamos com isso, e aí estão várias obras, aceitas pelo público, que negam essa tese aristocrática (GULLAR, 2002, p. 19).

Para reportagens de diversidade cultural, essa regularidade é muito importante, pois através do jornalismo é que podemos compreender a importância de uma identidade e aspecto cultural; por isso a mediação deve ser feita de forma acessível, muito bem explicada e contextualizada. $\mathrm{O}$ contrário pode gerar desentendimento até intolerância entre culturas de civilizações e localidades diferentes.

b) Caráter reflexivo: Uma segunda regularidade essencial do jornalismo cultural é seu caráter reflexivo. Este aspecto pode ser mais forte ainda neste segmento do jornalismo, já que desde seu nascimento, o jornalismo cultural se delineia pela análise crítica. A capacidade de levar 
o público a refletir deveria ser um diferencial do jornalismo cultural de outras editorias. Ou seja, enquanto as editoriais de economia, do dia a dia, de política, entre outras, noticiam as práticas, o jornalismo cultural pode e deve provocar a reflexão sobre essas práticas. A função do jornalismo cultural é revelar de forma clara e acessível "que, em toda grande obra, de literatura, de poesia, de música, de pintura, de escultura, há um pensamento profundo sobre a condição humana" (MORIN, 2001, p. 45).

E cabe ainda ressaltar aqui a função social do jornalismo cultural - que faz chegar a muitos o que estava restrito a poucos. O jornalista é um mediador, porém não basta somente fazer uma mera descrição do que vê. É cobrada dele uma responsabilidade profissional acrescida da necessidade de um olhar crítico, atento, e uma formação humanística sólida, "ciente da necessidade da codificação de uma realidade complexa, traduzindo-a em formas acessíveis e democráticas" (MELO, 2012, p. 06).

Para temáticas de diversidade cultural, o caráter reflexivo é de extrema importância. Fazer com que o público reflita sobre uma determinada cultura, um povo, uma manifestação cultural e popular reforça o combate a preconceitos e à intolerância entre culturas diferentes. Uma reportagem que desperta reflexão é melhor do que uma reportagem sobre cultura que alimenta um ponto de vista restrito e sectário, que faz se passar por universal.

\subsection{0 jornalismo cultural contemporâneo}

Vimos alguns pilares do jornalismo cultural: compromisso em mediar os conhecimentos, fazer uma crítica qualificada, tornar acessível, reflexivo e crítico o conhecimento cultural etc.

Independentemente de seus valores editoriais, é certo que a imprensa - por intermédio daquilo que seleciona como pauta e da ênfase que dá a alguns fatos em detrimento de outros - interfere na agenda pública e no consumo social dos bens culturais (SEGURA; GOLIN; ALZAMORA, 2011). "O campo jornalístico, seja no reforço da tradição ou na revelação de novas perspectivas, amplia o horizonte da recepção e detém o poder de incluir ou de excluir, de qualificar ou desqualificar, de legitimar ou não, de dar voz, publicizar e tornar público" (BERGER, 1996, p.190).

E o que se pratica hoje na grande mídia? Os jornalistas diplomados, na década de 1970, cobravam o espaço jornalístico, brigando contra a "linguagem hermética, a lógica argumentativa, os jargões e os excessos técnicos dos scholars acadêmicos. Visualizava-se ali a necessidade de atender ao leitor médio, público suposto e consumidor de jornais" (SEGURA; GOLIN; ALZAMORA, 2011, p 09).

Januário (2005) atesta, por meio de pesquisa quantitativa, que o jornalismo paulista, no período compreendido entre as décadas de 1980 e 1990, passou a ser constituído prioritariamente por peças informativas, em concordância com a agenda industrial e televisiva. Matérias de caráter crítico e analítico ficam em segundo plano. Equipes menores nas redações, a linha editorial dos veículos, os interesses econômicos e políticos, dentre outros fatores, contribuem para a padronização do jornalismo cultural, com reportagens meramente descritivas e superficiais, sem espaço para provocar reflexão, e muito centradas no serviço, na agenda, na divulgação e no celebrismo.

Conforme já divulgado através de Gadini (2006), os cadernos diários, no Brasil, se dedicam 
frequentemente à publicação de roteiros (serviços), à programação televisiva e às colunas sociais, além de variedades como horóscopo, palavras cruzadas, quadrinhos, restando menos da metade de espaço para conteúdos reflexivos ou críticos.

\subsection{Jornalismo cultural e a valorização das culturas regionais}

Após passarmos por uma explanação histórica e remontarmos o panorama atual do jornalismo cultural, permitimos chegar a algumas reflexões, e a partir disso falarmos mais do jornalismo e sua relação com a cultural local e regional.

Foi possível constatar que, por mais que o jornalismo cultural tenha sofrido muitas mudanças durante sua história, há sempre alguns aspectos que se mantêm vivos e potentes em sua trajetória, e diante desta análise encontramos duas regularidades fundamentais. Primeiro, a necessidade de democratizar o conhecimento e, segundo, seu caráter reflexivo. São elas que definem o jornalismo cultural como uma prática singular e importante para a sociedade. E ressaltamos ainda a função social do jornalismo cultural.

Entre essas considerações, ainda é oportuno colocar para reflexão a importância do jornalista cultural como mediador, pois cabe a ele traduzir uma realidade complexa em formas simbólicas acessíveis, sem que isso empobreça a informação. Cabe ainda a discussão sobre a responsabilidade profissional do jornalista cultural, que deve selecionar o que deve ser conhecido e como deve ser conhecido publicamente. Enfim, essas reflexões e definições de regularidades ajudam a nortear o trabalho do jornalista cultural em um grande veículo de comunicação, que por vezes acaba limitando sua prática a um fazer institucional, padronizado, ligado a interesses editoriais, econômicos e empresariais.

Importante ressaltar aqui que é relevante olhar para a cultura sem a dicotomia "cultura alta" versus "cultura baixa", mas saber diferenciar a autenticidade entre a cultura para as massas e a cultura, de fato, popular.

Essas considerações sobre o fazer jornalismo cultural são fundamentais quando o assunto se refere a manifestações culturais regionais, como o folclore e pautas que envolvem culturas minoritárias.

Mas por quais motivos valorizar a cobertura jornalística sobre o folclore, sobre a identidade local, os hábitos e crenças culturais etc.? Para a Organização das Nações Unidas para a Educação, a Ciência e a Cultura (Unesco) (2009, p.05), “[...] o contexto da globalização, o aumento das migrações e o crescimento das cidades, os desafios conexos com a preservação da identidade cultural e o fomento do diálogo intercultural adquirem uma nova projeção e tornam-se mais urgentes".

Neste cenário, a mídia é tida como importante instrumento de valorização e disseminação das culturas. Mas, assim como pode contribuir para valorizar e difundir, pode-se também provocar representações distorcidas, artificiais e estereotipadas. Isso sem falar que, notoriamente, pautas sobre a cultura popular e regional não são tão frequentes em nossa grande mídia, principalmente. A Unesco (2009, p. 20) aponta que as minorias étnicas, culturas minoritárias e outros grupos marginalizados estão ausentes na mídia, "em parte porque não têm acesso aos cargos editoriais, de gestão ou de tomada de decisão quanto ao que é publicado ou não nos veículos de mídia (gate-keeping)". 
Por mais que sejam escassas as pesquisas que investigam o tratamento dado às coberturas na área de cultura, de maneira geral percebe-se presente em pautas relacionadas à cultura local e regional, a forte característica do agendamento habitual dos veículos de comunicação, discutido anteriormente, e também do celebrismo. Quando se trata de eventos culturais, a grande mídia tende a pautar temas relacionados às tradições culturais apenas nos períodos já demarcados no calendário, e das festas mais conhecidas e pontuais.

Woitowicz (2012) reforça aspectos de agendamento conforme os estudos de observação que fez sobre a cobertura cultural de sites jornalísticos do Paraná (Gazeta do Povo, Paraná Online e Bem Paraná), no ano de 2011. "[...] Pode-se identificar alguns impasses para a cobertura de temas ligados à cultura popular, decorrentes da prevalência de uma cultura comercial na mídia, ao mesmo tempo em que se revelam apropriações e relações entre a cultura popular e os meios de comunicação" (WOITOWICZ, 2012, p.12).

A autora, em sua análise, registra a veiculação de reportagens que abordam a cultura popular, porém sempre reforçando o caráter de promoção de agenda. "A cultura como agenda é a principal marca da cobertura noticiosa, atuando muito mais como serviço do que como informação e compreensão dos fenômenos culturais". (WOITOWICZ, 2012, p.o8).

Sobre a característica do celebrismo, podemos examinar como clássicos de cobertura a festividade do Carnaval. De acordo com a observação de Moraes (2008), a cobertura da grande mídia fica restrita à divulgação da quantidade de turistas de outros países que chegam ao Brasil; ou então são focadas personagens famosas que desfilam nas escolas de samba do Rio de Janeiro e de São Paulo, tais como celebridades; os trios elétricos conduzidos por celebridades, muito comuns no Carnaval e que se tornaram grandes empresas do ramo de entretenimento, também ganham destaque nas coberturas. Percebem-se apelos ao entretenimento e à divulgação de celebridades instantâneas em contrapartida de coberturas que contribuam para a manutenção da identidade do povo brasileiro. "[...] toda a essência tradicional, que liga o presente ao passado de um povo é perdida ou, pelo menos, diminuída” (MORAES, 2008, documento eletrônico).

Moraes (2008) indica que, ao fazer isso, se reduz a cultura somente ao entretenimento, contribuindo para que se reforce nossa crise de identidade cultural. "Falta densidade e reflexão sobre os movimentos culturais e seus principais atores, tal como é proposto na definição do próprio jornalismo cultural" (MORAES, 2008, documento eletrônico).

A ausência de contextualização e maior profundidade das notícias e reportagens ligadas à cultura popular podem levar aos tão combatidos, porém naturalizados - os estereótipos culturais. Isso faz com que a diferença realçada possa gerar intolerância e falta de entendimento a respeito daquela cultura. "As culturas que pertencem a tradições de civilizações diferentes são especialmente inclinadas a recorrer a estereótipos mútuos” (UNESCO, 2009, p.09). Além disso:

[...] a escolha restrita das representações que propõem as grandes redes de mídia e de comunicação tendem a favorecer a criação de estereótipos, fabricando o que costumamos chamar uma "imagem do outro", manifestando cada meio de comunicação uma propensão específica para fixar, reduzir ou simplificar as coisas, em função de formatações e de programas uniformizados (UNESCO, 2009, p.19). 
Uma opção à visão restrita grande mídia sobre os acontecimentos culturais está na gama de veículos de comunicação, reforçada pelo advento do digital. Claro, atualmente há mais possibilidade de se fazer circular pautas sobre diversidade cultural, promovendo diálogo e expressão culturais. Mas, sobre isso, a Unesco (2009) alerta que nem sempre uma maior oferta e quantidade de conteúdos circulando pelas novas mídias e tecnologias significa diversificação do consumo:

O desenvolvimento da oferta de conteúdos midiáticos não resulta necessariamente em uma maior diversificação do consumo. Perante excesso de oferta, alguns consumidores preferem limitar-se a um pequeno número de títulos ou de temas conhecidos, em vez de se aventurarem em áreas desconhecidas ou diferentes. [...] O aumento da oferta de conteúdos da mídia pode dar lugar a uma falsa diversidade que oculta o fato de que a algumas pessoas só interessa comunicar com as que partilham as mesmas referências culturais. (UNESCO, 2009, p. 19).

$\mathrm{Na}$ internet, percebem-se movimentos, por meio de redes sociais, por exemplo, em que os públicos são compostos por "fãs" ou por "grupos", cujos "membros" quase não fazem contato uns com os outros, e com tendência para se limitar a outros modos de pensar. "Daí pode resultar uma falsa diversidade, que oculta, na realidade, o fato de que algumas pessoas só desejam comunicar com os que partilham as mesmas referências culturais" (UNESCO, 2009, p.19).

Em seu relatório mundial, denominado "Investir na diversidade cultural e no diálogo Intercultural", a Unesco (2009) sugere recomendações para a área de comunicação se tratando de conteúdos culturais. É importante analisar como esses conteúdos veiculados representam a realidade e que viés jornalístico tem sido dado à diversidade cultural, e coloca, dentre as múltiplas estratégias elaboradas para eliminar os estereótipos criados por essas representações da mídia, as iniciativas de alfabetização midiática e informacional, que podem auxiliar na formação de um público com maior espírito crítico quando consome produtos de comunicação, discordando e argumentando de pontos de vista parciais retratados pela mídia. Assim:

A alfabetização midiática é um aspecto importante do acesso aos meios e uma vertente fundamental da educação não formal. Convém promovê-la no seio da sociedade civil e junto aos profissionais de mídia, como parte integrante dos esforços que devem ser feitos para melhorar a compreensão recíproca e facilitar o diálogo intercultural (UNESCO, 2009, p.19).

Além de mencionar a importância da educação para a mídia, a Unesco também traçou três desafios/metas para que os conteúdos culturais e comunicacionais consigam contribuir para a diversidade cultural, independentemente da mídia. São três alicerces - a produção de conteúdos inovadores, a ampliação do acesso e a representação equilibrada, como se detalha a seguir:

Em primeiro lugar, há que responder aos imperativos da produção de conteúdos inovadores; em seguida, ampliar o acesso e, finalmente, lograr uma representação mais equilibrada. A produção de conteúdos inovadores deve garantir a integração da diversidade cultural à mídia e às indústrias culturais, privilegiando os conteúdos locais. A ampliação do acesso supõe, dentre outras, medidas coerentes para reduzir a exclusão digital, o acesso à produção e distribuição de conteúdos inovadores e o fomento de novas estratégias de informação e de comunicação que possam garantir a representação de pontos de vista contrá- 
rios nos debates sobre todos os temas. A diversidade cultural requer também uma representação equilibrada das diversas comunidades que convivem num determinado país, em conformidade com os princípios da liberdade de expressão e da livre circulação de ideias (UNESCO, 2009, p. 20)

Dentre mais ações recomendadas pela Unesco para a inclusão e valorização de pautas e conteúdos sobre a cultura popular, assim como para a formação de um olhar crítico a representações estereotipadas, estão:

a) Apoiar a produção e a distribuição de materiais audiovisuais inovadores e diversificados, considerando as necessidades locais, os conteúdos e os atores, recorrendo, conforme as necessidades, às parcerias público-privado; b) Avaliar o impacto das mudanças induzidas pelas TIC na diversidade cultural, a fim de destacar as boas práticas de acesso multilinguístico às produções escritas e audiovisuais; c) Promover, em todos os grupos etários, a iniciação aos meios de comunicação e à informática, para que os usuários desses meios tenham uma maior capacidade de avaliar criticamente a comunicação e os conteúdos culturais.

Destaca-se o item "c" como processo importante para a formação de público mais crítico quanto aos conteúdos culturais veiculados pela mídia. Resta ressaltar, em meio a isso, que o receptor da informação não é mais visto como um ser indefeso e apático diante do poder da mídia massiva. As audiências são plurais, e a recepção é tida como o lugar na qual ocorrem a negociação e a produção de sentido, com a participação de produtor e receptor (CERIGATTO; SIQUEIRA, 2008). Isso é válido também para os jornalistas e veículos de comunicação, que devem tomar cuidado com as representações que fazem da cultura popular, tendo em vista que o público não é homogêneo e passa cada vez mais a negociar com as mensagens produzidas.

\section{Conclusão}

A disseminação da imprensa, os avanços tecnológicos, entre outros fatores, permitiram que o jornalismo cultural começasse a ampliar-se para as camadas mais populares. A distinção entre a existência de cultura "alta" e uma cultura "baixa" perde força, mas o fenômeno da cultura de massa carrega características diferentes da cultura dita como popular. Enquanto a cultura popular mediatizada representa uma continuidade da arte anônima produzida em contato com o público, a cultura massificada destrói os laços de individualidade e as idiossincrasias do artista; enquanto a cultura popular permite ao artista exercitar um estilo pessoal reconhecível pelo público, a cultura massificada vende a pessoa do artista, mas não seu estilo pessoal. (CERIGATTO; SIQUEIRA, 2008).

Sabendo o lugar singular que a cultura popular ocupa, assim como suas diversas manifestações - locais, regionais, artísticas, religiosas etc. - as regularidades fundamentais do jornalismo cultural devem ser retomadas. A necessidade de democratizar o conhecimento e o caráter reflexivo são fundamentais para combater representações estereotipadas e distorcidas das identidades culturais. Assim, a cobertura por pautas que englobam o folclore e aspectos das diversas culturas devem ser trazidas à tona de maneira bem traduzida, com análises mais profundas que permitam a clareza e o acessível entendimento. Para isso, a contextualização é essencial. Reportagens que provocam a reflexão são importantes para evitar pontos de vista fechados a respeito daquela cultu- 
ra. "[...] é necessário perseverar nos esforços para limitar os estereótipos e os preconceitos a que as comunidades são frequentemente submetidas” (UNESCO, 2009, p. 32).

Além do esforço para uma cobertura mais aberta, reflexiva, contextualizada e cuidadosa quanto às representações distorcidas, frente à fragmentação de públicos - em que o contato com o diferente, de forma restrita e inadequada, pode gerar intolerância e incompreensão - destaca-se a importância de iniciativas de alfabetização midiática ou educação para a mídia, que visam fomentar uma postura mais equilibrada e crítica diante as representações veiculadas pela grande mídia a respeito da cultura popular, conforme recomendações da Unesco.

Por fim, vale mencionar que a mídia e o jornalismo cultural são peças chave fundamentais para a valorização da diversidade cultural, ad cultura popular e a promoção de diálogo entre culturas diferentes. A consciência dessa diversidade não pode ser banalizada, e nem as manifestações não podem ser reduzidas ao entretenimento, nem a um simples evento do calendário festivo, nem ao celebrismo. É importante que a mídia e o jornalismo reúnam esforços para a preservação da diversidade cultural, contribuindo para que a temática tenha maior notoriedade de forma adequada.

\section{Referências bibliográficas}

BERGER, Christa Liselote. Campos em confronto: jornalismo e movimentos sociais. São Paulo: Escola de Comunicações e Artes da Universidade Federal de São Paulo, 1996, 168p. (Tese de Doutorado).

BURKE, Peter. Uma história social da mídia: de Gutenberg à internet. Rio de Janeiro: Jorge Zahar, 2004.

CERIGATTO, Mariana Pícaro; SIQUEIRA, Alexandra Bujokas de. Media literacy: estudando o trailer do cinema no ensino médio. 2008. 9of. Trabalho de iniciação científica (graduação em jornalismo) - Universidade do Sagrado Coração, Bauru.

ECO, Umberto. Apocalípticos e Integrados. Coleção Debates. São Paulo: Perspectiva, 1979.

GADINI, Sérgio Luiz. A cultura como notícia no jornalismo brasileiro. Cadernos da Comunicação, Rio de Janeiro, Prefeitura da Cidade do Rio de Janeiro, v.8, 2003.

GULLAR, Ferreira. Cultura Posta em Questão - Vanguarda e Subdesenvolvimento. São Paulo: Editora José Olympio, 2002.

HALL, Stuart; WHANNEL, Paddy. The popular arts. Londres: Hutchinson Educational, 1964.

HALLORAN, James. D. e JONES, Marcia. Learning about media: communications and Society (Unesco papers). Paris: Unesco, 1986.

JANUÁRIO, Marcelo. O olhar superficial: as transformações no jornalismo cultural em São 
Paulo na passagem para o século XXI. 2005. Dissertação de Mestrado. Universidade de São Paulo, Programa de Pós-Graduação em Ciências da Comunicação, 2005.

MARCONDES FILHO, Ciro. Comunicação e jornalismo - a saga dos cães perdidos. São Paulo: Hacker Editores, 2000

MORIN, Edgar. A cabeça bem feita: repensar a reforma, reformar o pensamento. Rio de Janeiro: Bertrand, 2001.

PIZA, Daniel. Jornalismo cultural. São Paulo: Contexto, 2004.

SANTOS, Roberto Elísio. As teorias da comunicação: da fala à internet. Paulinas: São Paulo, 2003.

Referências eletrônicas

MAGALHÃES, Marina. Polarizações do jornalismo cultural. João Pessoa: Marca de Fantasia, 2010. Disponível em: <http://www.marcadefantasia.com/ebook/jornalismo-culturalebook. pdf >. Acesso em: 13 abr. 2014.

MELO, Isabelle Anchieta de. Jornalismo cultural: por uma formação que produza o encontro da clareza do jornalismo com a densidade e a complexidade da cultura. Disponível em: <http:// www.itaucultural.org.br/bcodemidias/000756.pdf>. Acesso em: 20 ago. 2012.

MORAES, Vaniucha de. Jornalismo cultural não valoriza tradições. Observatório da Imprensa. 08 abr. 2008. Disponível em: <http://observatoriodaimprensa.com.br/feitos-desfeitas/jornalismo_cultural_nao_valoriza_tradicoes/>. Acesso em: 02 mar. 2015.

SEGURA, Aylton; GOLIN; Cida; ALZAMORA, Gean. O que é Jornalismo Cultural. In: Jornalismo Cultural - Trajetórias e Reflexões. Rio Grande do Sul: UFRGS, 2011. Cap. 4, p. 1-20. Disponível em: <http://www.ufrgs.br/lead/producao_pesquisa/6.Segura_golin_alzamora.pdf >. Acesso em: 20 abr. 2012.

UNESCO. Relatório Mundial da Unesco: Investir na diversidade cultural e no diálogo intercultural. Paris: Organização das Nações Unidas para a Educação, a Ciência e a Cultura, 2009. Disponível em: <http://unesdoc.unesco.org/images/o018/o01847/184755por.pdf>. Acesso em: 20 jan. 2014.

WOITOWICZ, Karina Janz. A cultura popular na agenda midiática: Aspectos da produção jornalística no espaço cultural dos webjornais paranaenses. Cultura, Comunicação e Sociedade, Cáceres, v. 1, n. 1, p.o1-14, 2012. Jul-dez. Disponível em: $<$ http://www.aia.unemat.br/revistaculturasociedade/arquivos/artigo_Karina_editorado.pdf>. Acesso em: 16 maio 2013 